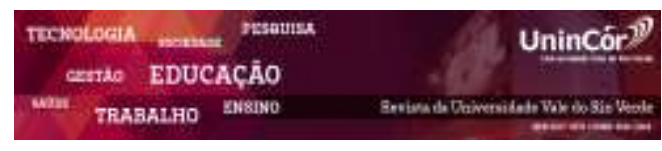

Revista da Universidade Vale do Rio Verde ISSN: 1517-0276 / EISSN: 2236-5362 Vol. 16 | n. 2 | Ano 2018

Tayanne Graciette Nascimento Silva Universidade Federal do Tocantins - UFT tay.graciette@gmail.com

Rafaella da Costa Gama Universidade Federal do Tocantins - UFT rafaellacg@yahoo.com.br

Lorena Gama Teixeira

Universidade Federal do Tocantins - UFT lorenagamaeng@gmail.com

Gil Rodrigues dos Santos Universidade Federal do Tocantins - UFT gilrsan@uft.edu.br

Rhonan Martins de Sousa Universidade Federal do Tocantins - UFT rohsousa@hotmail.com

Priscila Bezerra de Souza Universidade Federal do Tocantins - UFT priscilauft@uft.edu.br

\section{DIAGNÓSTICO AMBIENTAL DE UMA ÁREA DE PROTEÇÃO PERMANENTE (APP), FORMOSO DO ARAGUAIA - TO}

\section{RESUMO}

Objetivou-se diagnosticar os principais impactos incidentes na Área de Proteção Permanente (APP) da Fazenda Bom Sossego, município de Formoso do Araguaia, estado do Tocantins. Foi realizado uma caracterização do diagnóstico ambiental de uma Área de Proteção Permanente (APP) em Formoso do Araguaia TO de forma visual, através de uma matriz de aspectos e impactos ambientais na área analisada, utilizou-se uma trena métrica para efetuar a medida da Área de Proteção Permanente e máquina fotográfica para registrar os impactos presentes na área de estudo. Os principais impactos ambientais identificados na APP foram o desmatamento irregular, afugentamento da fauna local, compactação da camada superficial do solo, presença processos erosivos, pisoteamento do solo pelos bovinos e assoreamento do corpo hídrico. Os impactos ambientais observados são gerados pela criação desordenada de gado proveniente da expansão agropecuária pela falta de cuidados com a manutenção da área proteção ambiental analisada. Constatou-se um déficit de vegetação analisada na área, evidenciando assim a necessidade de medidas mitigatórias para conservação da área de proteção ambiental como recomposição vegetal da fisionomia mata de galeria, isolamento com cerca da área para que não haja a entrada do gado na área de proteção e monitoramento da área.

Palavras-chave: Impactos. Matriz de interação. Mitigação.

\section{ENVIRONMENTAL DIAGNOSIS OF A PERMANENT PRESERVATION AREA (PPA), FORMOSO DO ARAGUAIA - TO}




\section{INTRODUÇÃO}

O uso dos recursos naturais nas últimas décadas vem sendo uma das preocupações e questionamento por parte dos profissionais e da própria população, a grande discussão é sobre a preservação ambiental e a recuperação das áreas que sofrem processos de degradação. $\mathrm{O}$ desenvolvimento socioeconômico decorrente do crescimento industrial e agrícola juntamente com o crescimento populacional do mundo, tem aumentado significativamente a demanda sobre os recursos naturais, sendo que esta demanda é considerada bem maior que a capacidade de reposição dos recursos (FERREIRA, 2015).

Atualmente, o Cerrado é ameaçado devido à expansão efetiva da agropecuária, mediante as mudanças na vegetação nativa. Essa expansão da agropecuária vem sendo feita pelo uso de intensivo de agrotóxicos, fertilizantes e corretivos, uso inadequado da irrigação; monocultura em grande escala; uso de tecnologia química; pisoteio excessivo de animais. Isso tudo acontece devido ao grande desenvolvimento populacional, sendo o responsável pelos impactos ao bioma Cerrado e estimulando o crescimento das fronteiras agrícolas, proporcionando danos socioambientais (CUNHA, 2008).

A degradação ambiental mudou a caracterização do seu perfil, resultando no aumento do desmatamento, erosão, assoreamento das nascentes e rios, contaminação da água subterrânea, compactação do solo, com consequência em todo ecossistema (CUNHA, 2008).

Segundo Fernandes (2015) além dos processos erosivos a degradação do meio ambiente vem contribuindo para a poluição das águas, pois as matas ciliares são fundamentais para a proteção dos recursos hídricos. Podendo comprometer a quantidade de água disponível e a qualidade de água potável (FERREIRA, 2016).

As Áreas de Preservação Permanente (APP) possuem relevância em relação a conservação da água e são consideradas áreas nas quais, por lei, sua vegetação deve encontrarse intactas para garantir a preservação dos recursos hídricos, a estabilidade geológica e a biodiversidade, ser mantida preservado conforme Brasil (2012) estabelece o Novo Código Florestal Federal (Lei 12651/12tucc).

A importância das APP se dá pelo fato de ser uma proteção efetiva dos corpos d'água, uma vez que a vegetação presente nessa área atua como um obstáculo para o escoamento superficial, o que favorece a infiltração e minimiza o risco de erosão nessas áreas. Diminuindo o risco de erosão, diminui-se também o assoreamento desses corpos d'água, fazendo com que seu nível de água se mantenha o mais natural possível. Além de beneficiarem os 
corpos d'água, as APP servem como da biodiversidade, o que é providencial para a fauna e a flora de uma determinada região (GUIMARÃES, 2015).

É importante ter conhecimento que o regime de proteção das APPs é considerado rígido por estabelecer que as áreas estejam protegidas, sendo admitida a retirada da vegetação somente quando for casos de utilidade pública e interesse social, se estiverem previstos na legislação, conforme a Lei n ${ }^{o} 17.727$ do Novo Código Florestal Federal.

A degradação ambiental de uma Área de Preservação Permanente (APP) interfere de madeira direita na área ao seu redor, modificando o entorno no qual deveria ser protegido, no qual deveria haver manutenção de forma natural. Por isso é de grande importância a preservação e recuperação ambiental, sendo isso previsto por lei (GUIMARÃES, 2015).

Os impactos ambientais devem ser avaliados através do diagnostico ambiental, que tem como base interpretar a situação em que se encontra o ambiente de uma determinada área, buscando conhecer os seus componentes ambientais, através da matriz de interação que é considerado um dos métodos mais utilizados dentro dos estudos dos impactos ambientais (CÂNDIDO et al., 2017).

Cândido et al. (2017), Gonçalves et al. (2016) e Neres et al. (2015) utilizaram matriz de interações para realizar um diagnóstico ambiental e propor medidas mitigadoras para APP em municípios na região Sul do estado do Tocantins. A realização do diagnostico ambiental é fundamental para definir a situação em que se encontra a área analisada, sendo importante destacar que é de obrigação do proprietário a averbação da Reserva Legal e da recomposição vegetal, sendo de fundamental importância a realização do levantamento florístico e fitossociológico nas propriedades rurais conforme a legislação do Código Florestal Federal, entretanto atualmente, existem poucos estudos realizados sobre a real situação das APPs e Reservas Legais das propriedades rurais do estado do Tocantins.

Diante do contexto, objetivou-se diagnosticar os principais impactos incidentes na Área de Proteção Permanente (APP) da Fazenda Bom Sossego, município de Formoso do Araguaia, Tocantins.

\section{MÉTODOS}

O diagnóstico ambiental foi realizado em uma Área de Preservação Permanente - APP com área total de 16 ha pertencente a Fazenda Bom Sossego no Município de Formoso do Araguaia - TO, sob as coordenadas 11 ${ }^{\circ} 53$ '35" S 49 $25^{\prime} 16^{\prime \prime}$ W. O clima predominante da região é C2wA"a", úmido subúmido com duas estações bem definidas, uma seca de maio a setembro e uma chuvosa de outubro a abril, com moderada deficiência hídrica no inverno, precipitação média anual em torno de 1.600 a 1.700 mm, com temperatura média anual entre 25 e $26^{\circ} \mathrm{C}$ e 240 m de altitude (SEPLAN, 2012).

Para o diagnóstico, realizou-se duas visitas técnicas nas nascentes para levantamento dos dados dentro da área de 16 ha. O diagnóstico ambiental da APP foi feito por meio da identificação dos impactos que ocorrem sobre a 
área analisada e interação das ações que impactam de forma direta e indireta o local.

Esta caracterização da área ocorreu de forma visual, pelo meio do uso de listagem de impactos ambientais, trena métrica para efetuar a medida da Área de Preservação Permanente e máquina fotográfica para registrar os impactos presentes na área de estudo, conforme a metodologia adotada por Ferreira (2015) e Rodrigues et al. (2015) que considera os aspectos adotados na tabela 1 para elaboração das ações impactantes e suas respectivas mitigações. A avaliação realizada utilizou seis critérios para identificar os impactos e classificar qualitativamente e quantitativamente a área diagnosticada (Tabela 1).

O método de listagem referente aos parâmetros adotados utilizou-se a Resolução do CONAMA 001 (1986) que classifica os impactos ambientais. Sequencialmente foram definidas algumas propostas de medidas de mitigação para serem adotadas na área de estudo.

Tabela 1 - Matriz de caracterização dos impactos ambientais

\begin{tabular}{|c|c|c|c|}
\hline Aspectos & $\mathbf{P A}$ & $\mathbf{P} / \mathbf{S}$ & Descrição do parâmetro \\
\hline Valor/ & Negativo & $\mathrm{N}$ & Resulta na possibilidade de ocorrer um impacto de caráter significativo. \\
\hline \multirow{2}{*}{ Efeito } & Positivo & $\mathrm{P}$ & Resulta no benefício das atividades ou impactos da APP. \\
\hline & Nulo & $\mathrm{O}$ & Resulta em um fator cujos efeitos inexistem. \\
\hline \multirow[b]{2}{*}{ Ordem } & Direto & $\mathrm{D}$ & Resulta de uma simples relação de causa e efeito. \\
\hline & Indireto & I & $\begin{array}{l}\text { Resulta de uma ação secundária ou quando é parte de uma cadeia de } \\
\text { reações, também denominada de Impacto Secundário. }\end{array}$ \\
\hline \multirow{3}{*}{ Espaço/ Escala } & Local & Lo & Quando afeta apenas a área local do empreendimento. \\
\hline & Regional & $\operatorname{Re}$ & Quando o efeito extrapola a área de implantação do empreendimento \\
\hline & Estratégico & $\mathrm{E}$ & Quando o efeito assume reflexo estadual ou nacional. \\
\hline \multirow{3}{*}{ Dinâmica } & Temporário & $\mathrm{T}$ & $\begin{array}{l}\text { Quando o efeito do impacto permanece por um determinado tempo, } \\
\text { após o qual depois desaparece }\end{array}$ \\
\hline & Permanente & $\mathrm{Pe}$ & $\begin{array}{l}\text { Quando os efeitos não cessam de se manifestar num horizonte temporal } \\
\text { conhecido. }\end{array}$ \\
\hline & Cíclico & $\mathrm{C}$ & Quando os efeitos se fazem sentir de forma cíclica ou periódica. \\
\hline \multirow{3}{*}{ Tempo } & Curto & $\mathrm{C}$ & A ação permanece num curto espaço de tempo. \\
\hline & Médio & $\mathrm{Me}$ & A ação pode ser cessada após um tempo. \\
\hline & Longo & $\mathrm{L}$ & O impacto pode ser considerado irreversível. \\
\hline \multirow[b]{2}{*}{ Plástica } & Reversível & $\mathrm{R}$ & O local pode voltar a ter a paisagem original. \\
\hline & Irreversível & $\mathrm{Ir}$ & $\begin{array}{l}\text { Após a ação impactante, mesmo com medidas mitigadoras, o local não } \\
\text { volta a ter a paisagem original. }\end{array}$ \\
\hline \multirow{3}{*}{ Magnitude } & Pequena & $1-3$ & O meio permanece inalterado. \\
\hline & Média & $4-6$ & $\begin{array}{l}\text { O meio apresenta uma leve alteração quanto à sua paisagem, porém de } \\
\text { forma inexpressiva. }\end{array}$ \\
\hline & Grande & $7-10$ & A ação altera toda a paisagem \\
\hline \multirow{3}{*}{ Frequência } & Baixa & 1 & Sem danos ou com danos mínimos ao meio ambiente. \\
\hline & Média & 2 & $\begin{array}{l}\text { O meio apresenta uma leve alteração quanto à sua paisagem, porém de } \\
\text { forma inexpressiva. }\end{array}$ \\
\hline & Alta & 3 & A ação altera toda a paisagem. \\
\hline \multirow[t]{2}{*}{ Significância } & $\begin{array}{l}\text { Não } \\
\text { significativa }\end{array}$ & $1-3$ & $\begin{array}{l}\text { O impacto provocado não altera a qualidade de vida do meio ou do } \\
\text { homem. }\end{array}$ \\
\hline & Moderada & $4-6$ & A área lesionada pela ação, quando negativa, pode ser recuperada e \\
\hline
\end{tabular}


quando positiva, apresenta uma melhoria razoável na qualidade de vida.

A ação impactante apresenta uma significativa evolução benéfica ao Significativa $\quad 7-9$ meio ambiente, quando positiva, e uma perda na qualidade de vida quando negativa.

PA - Parâmetros de Avaliação; P/S - Pontuação/Símbolo.

Fonte: Rodrigues et al. (2015)

\section{RESULTADOS E DISCUSSÃO}

Constatou através do diagnostico ambiental que os impactos ambientais identificados por meio da matriz de interação foram ocasionados principalmente pela criação de gado (pecuária intensiva), fato este que altera a dinâmica ecológica da Área de Preservação Permanente (APP), além desse impacto foram identificados outros, entretanto foram classificadas e sugeridas medidas mitigadoras para minimizar os efeitos dos impactos (Tabela 2).

Tabela 2 - Matriz de caracterização dos impactos ambientais observados na APP da Fazenda Bom Sossego em Formoso do Araguaia - TO

\section{Avaliação de Aspectos e Impactos Ambientais}

\begin{tabular}{|c|c|c|c|c|c|c|c|c|c|c|}
\hline Ação Impactante & 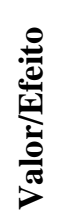 & $\frac{\Xi}{0}$ & 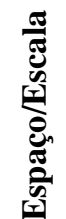 & 芯 & & 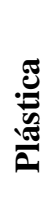 & 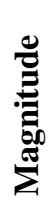 & & 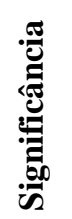 & Medidas Mitigadoras \\
\hline
\end{tabular}

$\begin{array}{lllllllllll}\text { Desmatamento } & \mathrm{N} & \mathrm{D} & \text { Lo } & \text { Pe } & \mathrm{Me} & \text { Ir } & 7 & 3 & 3 & \begin{array}{c}\text { Isolar a Área de Proteção Permanente com } \\ \text { barreira física e reflorestar a área impactada }\end{array}\end{array}$

$\begin{array}{cccccccccccc}\begin{array}{c}\text { Afugentamento da } \\ \text { fauna local }\end{array} & \mathrm{N} & \mathrm{I} & \text { Lo } & \mathrm{T} & \mathrm{Me} & \mathrm{R} & 4 & 1 & 2 & \text { Plantio de mudas nativas frutíferas } \\ \begin{array}{c}\text { Compactação da } \\ \text { camada superficial }\end{array} & \mathrm{N} & \mathrm{I} & \text { Lo } & \mathrm{Pe} & \mathrm{Me} & \mathrm{R} & 6 & 3 & 4 & \begin{array}{c}\text { Gradear e isolar a Área de Proteção } \\ \text { Permanente com barreira física }\end{array}\end{array}$

$\begin{array}{ccccccccccccc}\begin{array}{c}\text { Presença de } \\ \text { processos erosivos }\end{array} & \text { N } & \text { I } & \text { Lo } & \text { T } & \text { L } & \text { Ir } & 9 & 3 & 4 & \begin{array}{c}\text { Reflorestamento da área impactada para a } \\ \text { cobertura do solo exposto. }\end{array} \\ \begin{array}{c}\text { Presença de bovinos } \\ \text { na APP }\end{array} & \text { N } & \text { D } & \text { Lo } & \text { Pe } & \text { C } & \text { R } & 6 & 3 & 2 & \text { Isolar a Área de Proteção Permanente } \\ \begin{array}{c}\text { Assoreamento dos } \\ \text { Corpos Hídricos }\end{array} & \text { N } & \text { I } & \text { Lo } & \text { T } & \text { L } & \text { Ir } & 9 & 3 & 5 & \text { Técnicas de revegetação do solo }\end{array}$

$\mathrm{N}$ = Negativo; $\mathrm{D}=$ Direto; $\mathrm{I}=$ Indireto; $\mathrm{L}=$ Longo; $\mathrm{Pe}=$ Permanente; $\mathrm{T}=$ Temporário; $\mathrm{M}=$ Moderado; $\mathrm{C}=\mathrm{Curto} ; \mathrm{Me}$ = Médio; $\mathrm{R}=$ Reversível; $\mathrm{Ir}=$ Irreversível; Lo = Local.

Fonte: Autores

$$
\text { O desmatamento da área avaliada é }
$$
considerado de ordem direta, no espaço local, sendo provocado devido à intensificação da agropecuária na região propiciando uma elevada 
perda da biodiversidade. Isso ocorre devido a expansão das atividades produtivas provocando mudanças no uso da terra, no qual colocou a agricultura brasileira como um dos responsáveis pelo uso de fertilizantes, defensivos agrícolas, maquinários, suplementos, quanto na pecuária, pelas áreas desmatadas e a criação de bovinos que emitem Metano (CH4), (SANTOS, 2017).

A ação antrópica que provoca o desmatamento da APP diagnosticada é gerada da agropecuária, que tem conduzido, ao passar dos anos, à ocupação desordenada da região do cerrado e, consequentemente acelerada degradação (QUEIROZ, 2009).

A área desmatada da APP diagnosticada apresenta indícios para os processos erosivos que têm deteriorações físicas e químicas do solo além das perdas de nutrientes ocasionado pelo transporte de sedimentos (FIGUEIREDO, 2015).

Portanto, o estudo prevê que a área de APP avaliada necessita de um isolamento da área com barreira física como por exemplo, uma cerca viva e reflorestamento para recuperar a área, isso através de plantio de espécies nativas da região do Cerrado, para o enriquecimento das espécies como forma de mitigação dos impactos gerados pelo desmatamento.

Conforme as análises de Melo (2004), as espécies analisadas (Anadenanthera falcata, Inga laurina e Planthymenia reticulata) podem ser recomendadas para o reflorestamento do Cerrado, sendo de baixo nível de manutenção. Além disso, Durigan (2004) afirma que algumas espécies exóticas são recomendadas em locais onde a diversidade florística seja mais lenta, pela sua rapidez do crescimento da estrutura florestal.
Com relação á afugentamento da fauna local, foi caracterizado com ordem indireta, dinâmica temporária e com efeitos reversíveis desde que se faça o plantio de mudas nativas frutíferas como por exemplo: araticum (Annona crassiflora Mart.), cajuzinho (Anacardium othonianum Rizz.), cagaita (Eugenia dysenterica D.C.), piqui (Caryocar brasiliense Camb.) como proposta de medida mitigatória.

A compactação da camada superficial é de ordem direta, com ocorrência local e dinâmica permanente, portanto devem ser realizadas as medidas mitigatórias como isolamento e gradeamento da área de proteção com barreira física (Figura 1).

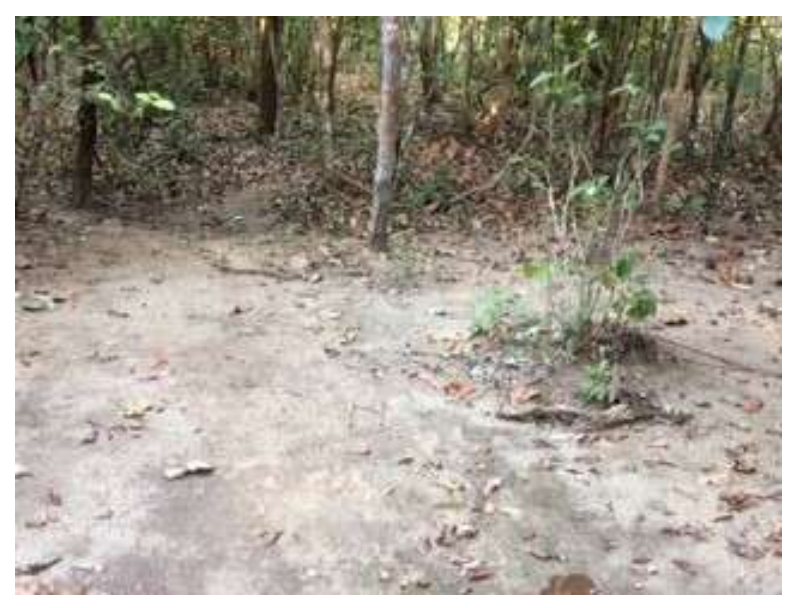

Figura 1 - Compactação do solo da Área de Proteção Permanente

Fonte: Autores

$$
\text { Segundo Gonçalves (2016) a }
$$
compactação contribui para a diminuição da porosidade e da permeabilidade do solo, provocando a diminuição na retenção de água tendo como consequência final o assoreamento.

Com a presença de bovinos na APP estudada foi observado que uma serie de impactos são gerados como por exemplo, a compactação do solo que dificulta a infiltração de agua no solo, causando dificuldades na 
germinação se sementes e consequentemente desaparecimento de espécies e perda da biodiversidade. Essa ação impactante apresenta ordem direta e espaço local, tendo como mitigação o isolamento da área de proteção.

Foi verificado a presença de processos erosivos e classificados com ordem indireta e dinâmica temporal (Figura 2). Tendo sua causa ocasionada pela a água da chuva e pelo escoamento superficial, afetada por agentes naturais e androgênicos (DA SILVA et al., 2007). De acordo com Pereira et al. (2014) as áreas degradadas têm perdido seus sedimentos devido ao escoamento superficial que aumenta a quantidade de solo dentro dos sistemas fluviais, provocando assim o desequilíbrio dessa área.

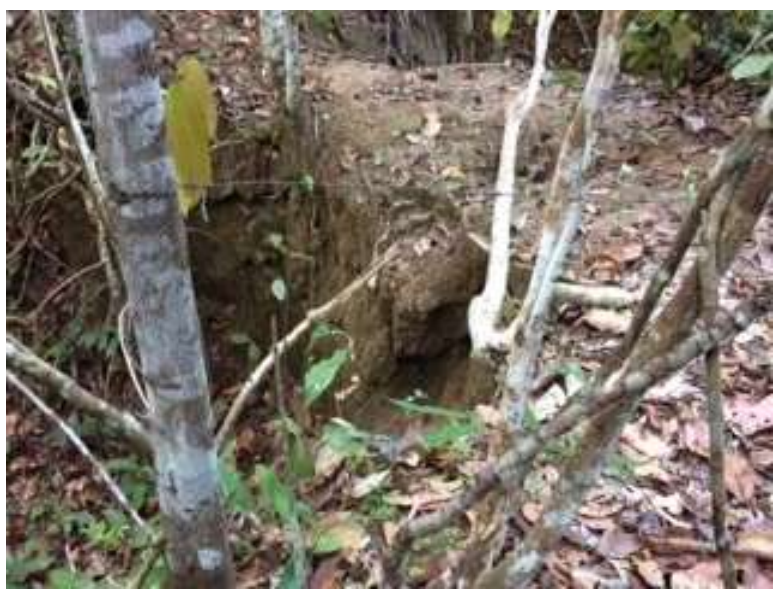

Figura 2 - Presença de processo erosivo na APP da fazenda Bom Sossego

Fonte: Autores

O assoreamento dos corpos hídricos encontrado dentro da Área de Proteção Permanente apresenta aspectos de ordem indireta, dinâmica temporal em um espaço local (Figura 3).

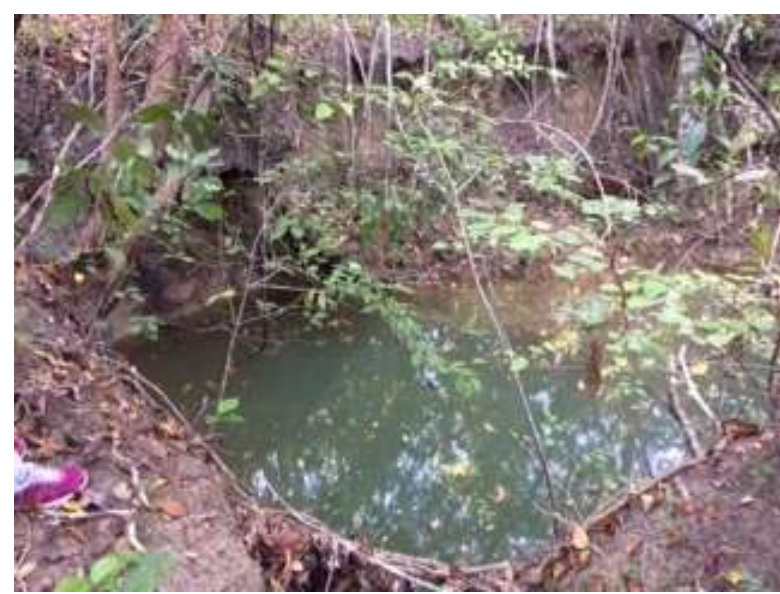

Figura 3 - Assoreamento do corpo hídrico da nascente dentro da área analisada

Fonte: Autores

O assoreamento tem origem de um processo natural, porém é intensificado com as atividades agropecuárias ocorridas no entorno da APP. Conforme exposto por Nunes et al. (2014), o assoreamento dos cursos d'águas é um grande problema para a conservação das condições normais dos corpos hídricos, causam algumas alterações e desequilíbrios nos seus aspectos hidrodinâmicos, que com o passar do tempo facilitam o surgimento de bancos de areias no seu leito.

O assoreamento diagnosticado no presente estudo é consequência da retirada da mata de galeria no qual relata Mota et al. (2016), que a área degradada que está compactada, sofre alteração devido a mudanças do regime de infiltração do solo que promove o transporte de sedimentos. Lourenço (2016), caracteriza o processo de assoreamento como a perda e transporte de sedimentos para o leito do rio, originários principalmente da retirada da cobertura vegetal, provocando uma cadeia repletas de perdas na biodiversidade da área, como por exemplo, a fauna e flora que sofre esse tipo de impacto ambiental. Tendo o trabalho 
como colaborador para a proteção dessa área impactada.

A área que está ocorrendo o assoreamento dentro da APP necessita de revegetação do solo como forma de mitigação desse impacto, pois só assim minimizará o transporte de sedimentos para o corpo d'água.

\section{CONCLUSÃO}

Foi diagnosticado que a Área de Proteção Permanente estudada apresenta alguns impactos ambientais, tais como, a compactação da camada superficial devido a presença de bovinos, surgindo assim processos erosivos devido falta de infiltração do solo, ocasionando assim em outros impactos como o assoreamento das nascentes que são provocados também pelo o desmatamento da APP o dificulta o recrutamento da fauna local ou afugenta por falta de abrigo e recursos naturais.

Portanto, é fundamental o cumprimento de medidas de mitigação que promovam a proteção e preservação da APP como: gradeamento da área de proteção, reflorestamento da área desmatada.

Além disso, é necessário o aumento da fiscalização, o monitoramento e controle da área de preservação dentro da propriedade conforme Brasil (2012) regulamenta o Novo Código Florestal Federal (Lei 12651/12).

\section{REFERÊNCIAS}

BRASIL. Leis e Decretos. Lei Federal n ${ }^{\circ} 12.651$, de 25 de maio de 2012. Institui o Novo Código Florestal Brasileiro. Brasília: 2012.
CÂNDIDO, J. B. et al. Diagnóstico ambiental e análise temporal dos impactos ambientais causados por um depósito de resíduos sólidos no município de Cariri do Tocantins - TO. Nucleus, v. 14, n. 1, p. 125140, 2017. Disponível em: <http://dx.doi.org/10.3738/1982.2278.1736>. doi: $10.3738 / 1982.2278 .1736$

CONAMA, Resolução No 001 de janeiro de 1986. Estabelece as definições, as responsabilidades, os critérios básicos e as diretrizes gerais para uso e implementação da Avaliação de Impacto Ambiental como um dos instrumentos da Política Nacional do Meio Ambiente, 1986.

CUNHA, N. R. D. S.; LIMA, J. E. D.; GOMES, M. F. D. M.; BRAGA, M. J. A intensidade da exploração agropecuária como indicador da degradação ambiental na região dos Cerrados, Brasil. Revista de Economia e Sociologia Rural, v. 46, n. 2, p. 291-323, 2008. Disponível em: <http://dx.doi.org/10.1590/S010320032008000200002>. doi: 10.1590/S010320032008000200002

DA SILVA, A. M. et al. Estudo integrado do processo erosivo numa microbacia experimental localizada no município de Cunha-SP. Geociências (São Paulo), v. 24, n. 1, p. 43-53, 2007. Disponível em: <http://www.ppegeo.igc.usp.br/index.php/GEOSP/arti cle/view/9739>.

MELO, A. C. G.; DURIGAN, G.; KAWABATA, M. Crescimento e Sobrevivência de Espécies Arbóreas Plantadas em Área de Cerrado, Assis SP. 2004.

DURIGAN, G. et al. Regeneração natural da vegetação de Cerrado sob florestas plantadas com espécies nativas e exóticas. Pesquisas em conservação e recuperação ambiental no oeste paulista: resultados da cooperação Brasil/Japão. São Paulo: Instituto Florestal, p. 349-362, 2004.

FERNANDES, M. M. F.; CEDDIA, M. B.; FRANCELINO, M. R.; FERNANDES, M. R. M. Diagnóstico ambiental da faixa ciliar e qualidade de água de duas microbacias utilizadas para abastecimento humano. IRRIGA, v. 20, n. 1, p. 128138, 2015. Disponível em: <http://dx.doi.org/10.15809/irriga.2015v20n1p128>. doi: 10.15809/irriga.2015v20n1p128

FERREIRA, C. et al. Análise socioambiental em propriedades rurais com nascentes em processo de recuperação no município de Lauro Muller

(SC). Revista Ciência \& Cidadania, v. 2, n. 1, p. 92 102, 2016. Disponível em:

$<$ http://periodicos.unibave.net/index.php/cienciaecida dania/article/view/52>.

FERREIRA, R. Q. S. et al. Diagnóstico ambiental do córrego Mutuca, Gurupi-TO. Revista Verde de 
Agroecologia e Desenvolvimento Sustentável, v. 10, n. 4, p. 08-12, 2015. Disponível em:

<http://dx.doi.org/10.18378/rvads.v10i4.3146>. doi: 10.18378/rvads.v10i4.3146

FIGUEIREDO, T. D.; FERREIRA, E. G.; DINIZ, C. E. Avaliação do nível de degradação ambiental por processos erosivos na comunidade de Utinga-Santa Rita PB. Revista Ambiental, v. 1, n. 2, p. 76-85, 2015. Disponível em:

<http://www2.fpb.edu.br/revista/index.php/eng_amb/a rticle/view/22/34>.

GONÇALVES, D. S.; SOUZA, P. A.; OLIVEIRA, A. L.;MARTINS, T. S. Diagnóstico ambiental e proposta de plano de recuperação da APP, Fazenda Santa Juliana, Cariri do Tocantins-TO. Nucleus, v. 13, n. 1, p. 261-276, 2016. Disponível em:

<http://www.nucleus.feituverava.com.br/index.php/nu cleus/article/view/1562/1983>. doi:

$10.3738 / 1982.2278 .1562$

GUIMARÃES, B. B.; GUIMARÃES, R. B.; LEAL, A. C. Código Florestal brasileiro: análise do conceito de Área de Preservação Permanente e sua aplicação na bacia hidrográfica do Córrego São Pedro-Anhumas, São Paulo. Boletim Campineiro de Geografia, v. 5, n. 1, p. 157-173, 2015. Disponível em: <http://agbcampinas.com.br/bcg/index.php/boletimcampineiro/article/view/192>.

LOURENÇO, S. T. S. et al. Diagnóstico ambiental de um fragmento de mata ciliar do rio Tocantins.

Enciclopédia Biosfera, v. 13, n. 24, p. 1189 - 1201, 2016. Disponível em:

<http://www.conhecer.org.br/enciclop/2016b/biologic as/diagnostico\%20ambiental.pdf $>$. doi:

10.18677/EnciBio_2016B_111

MOTA, A. R. et al. Diagnóstico ambiental no córrego Bacaba, Talismã-TO. Revista Verde de

Agroecologia e Desenvolvimento Sustentável, v. 11, n. 1, p. 14-19, 2016. Disponível em:

<http://dx.doi.org/10.18378/rvads.v11i1.3893>. doi:

10.18378/rvads.v11i1.3893

NERES, N. G. C. et. al. Avaliação ambiental e indicação de medidas mitigadoras para a nascente do Córrego Mutuca, Gurupi-TO. Enciclopédia Biosfera, v. 11, n. 21, p. 2824-2834, 2015. Disponível em: <http://www.conhecer.org.br/enciclop/2015b/multidis ciplinar/avaliacao\%20ambiental\%20e\%20indicacao.p df>. doi: DOI: 10.18677/EnciBio_2016B_111

NUNES, H. K. B.; GOMES, M. L.; PAULA, J. E. A.; Assoreamento e formação de bancos de areia no leito do rio Parnaíba, na zona urbana de Teresina-Piauí.

Revista Geonorte, v. 10, n. 1, p. 156-160, 2014.

Disponível em:

<http://www.periodicos.ufam.edu.br/revistageonorte/article/view/1537>.
PEREIRA, L. S. et al. Diagnóstico de processo hidroerosivo em área degradada por meio de monitoramento de estação experimental em Ubatuba/SP. Revista Geonorte, v. 5, n. 23, p. 326331, 2014. Disponível em: < http://periodicos.ufam.edu.br/revistageonorte/article/view/1717>.

QUEIROZ, F. A. Impactos da sojicultora de exportação sobre a biodiversidade do Cerrado. Sociedade \& Natureza, v. 21, n. 2, p. 193-209, 2009. Disponível em: <http://dx.doi.org/10.1590/S198245132009000200013>. doi: 10.1590/S198245132009000200013

RODRIGUES, A.J.; PEREIRA, M.A.; MARTINS, I.C.M.; SOUZA, P.A. Diagnóstico ambiental de um trecho da área de preservação permanente (APP), margens do córrego pouso do meio, em Gurupi-TO. Enciclopédia Biosfera, v. 11, n. 21, p. 2015 - 3103. Disponível em: <

http://www.conhecer.org.br/enciclop/2015b/multidisci plinar/Diagnostico\%20ambiental\%20de\%20um\%20tr echo.pdf $>$.

SANTOS, P. S. et al. Modelos tecnológicos aplicados na agropecuária brasileira e suas dimensões sociotécnicas e ambientais. Desafio Online, v. 5, n. 2, p. 221-241, 2017. Disponível em:

<http://www.seer.ufms.br/index.php/deson/article/vie w/2908>.

SEPLAN - SECRETÁRIA DE PLANEJAMENTO DO TOCANTINS. Atlas do Tocantins: subsídios ao planejamento da gestão territorial. Palmas. Atual, v.6, 2012.

\begin{tabular}{l}
\hline Tayanne Graciette Nascimento Silva \\
Engenheira Ambiental, Especialista em Engenharia \\
de Segurança do Trabalho, mestranda em Ciências \\
Florestais e Ambientais - UFT.
\end{tabular}

\section{Rafaella da Costa Gama}

Engenheira Florestal, mestranda em Ciências Florestais e Ambientais - UFT.

\begin{tabular}{l}
\hline Lorena Gama Teixeira \\
Engenheira Florestal, mestranda em Ciências \\
Florestais e Ambientais - UFT.
\end{tabular}

\footnotetext{
Gil Rodrigues dos Santos

Agrônomo, Doutor em Fitopatologia, Prof. Adjunto do Curso de Agronomia, Prof. do Programa de Pósgraduação em Ciências Florestais e Ambientais UFT.
} 
Rhonan Martins de Sousa

Engenheiro Florestal, mestre em Ciências Florestais e Ambientais - UFT.

\section{Priscila Bezerra de Souza}

Bióloga, Doutora em Botânica, Prof. Adjunta do

Curso de Engenharia Florestal, Prof. do Programa de Pós-graduação em Ciências Florestais e Ambientais UFT. 